\title{
Acute Upper-Airway Obstruction by a Lingual Thyroglossal Duct Cyst and Implications for Advanced Airway Management
}

\author{
Kanecia O Zimmerman MD MPH, Susan R Hupp MD, Ali Bourguet-Vincent MD, \\ Erin A Bressler MD, Eileen M Raynor MD, David A Turner MD, and Kyle J Rehder MD
}

\section{Introduction}

Respiratory failure in infants and children is a common cause of ICU admission, and diseases that jeopardize the airway are the most frequent cause of cardiac arrest in neonatal and pediatric patients. ${ }^{1,2}$ In neonates specifically, there are numerous causes for respiratory distress, with upper-airway obstruction being an important source of morbidity and mortality. ${ }^{3,4}$ This case will discuss the diagnosis and management of acute upper-airway obstruction and subsequent difficult-airway management in a previously well neonate.

\section{Case Summary}

An 18-d-old term infant with an unremarkable perinatal and birth history presented to the emergency department with acute-onset severe respiratory distress. Prior to presentation, the patient had no evidence of fever, fussiness, or congestion. Family members reported a nonproductive cough and intermittent noisy breathing since birth, with increased noisiness during feeding. On presentation, the patient was noted to be tachypneic, with a breathing frequency of 70 breaths/min, significant sternal retractions, nasal flaring, and oxygen desaturation. Lung exam revealed poor aeration bilaterally, but perfusion was adequate.

Drs Zimmerman, Hupp, Turner, and Rehder are affiliated with the Division of Pediatric Critical Care Medicine, Department of Pediatrics; Dr Bourguet-Vincent and Bressler are affiliated with the Department of Pediatrics; and Dr Raynor is affiliated with the Division of Otolaryngology, Department of Pediatric Surgery, Duke Children's Hospital, Durham, North Carolina.

The authors have disclosed no conflicts of interest.

Correspondence: Kanecia O Zimmerman MD MPH, Division of Pediatric Critical Care, DUMC, Box 3046, Durham, NC 27710. E-mail: kanecia.obie@dm.duke.edu.

DOI: $10.4187 /$ respcare. 02513
Due to impending respiratory failure, providers emergently initiated modified rapid-sequence intubation using atropine for premedication and etomidate for sedation. Providers ensured ability to bag-mask ventilate prior to paralysis with rocuronium. Vocal cords were not visualized on the initial intubation attempt. The infant was bag-maskventilated, and oxygen saturations were maintained initially, but ventilation and oxygenation became progressively more difficult with increased abdominal distention. Progressive hypoxia led to a brief bradycardic arrest during continued attempts to establish an artificial airway, and the subject received chest compressions, epinephrine, and atropine prior to restoration of adequate heart rate. During attempts, the emergency airway, pediatric anesthesia, and pediatric otolaryngology teams were called. Successful endotracheal intubation was achieved with a $2.5-\mathrm{mm}$ uncuffed endotracheal tube on the tenth attempt by the fifth provider, the pediatric otolaryngology attending. Hyperextension of the neck and cricoid pressure were required, and despite these manipulations, the airway was described as anteriorly displaced with a grade III view. Advanced airway devices such as a laryngeal mask airway or fiberoptic scope were not used during intubation. Upon intubation, gas exchange improved immediately, and the subject was transported to the pediatric ICU for further evaluation and management.

Initial examination in the pediatric ICU showed no facial dysmorphisms, adequate perfusion in all extremities, no cardiac murmur, and clear breath sounds bilaterally. Laboratory studies included an arterial blood gas with $\mathrm{pH}$ 7.38, $\mathrm{P}_{\mathrm{aCO}_{2}} 32 \mathrm{~mm} \mathrm{Hg}$, and $\mathrm{P}_{\mathrm{aO}_{2}} 324 \mathrm{~mm} \mathrm{Hg}$ at $\mathrm{F}_{\mathrm{IO}_{2}} 1.0$. There was no organ dysfunction as evidenced by normal liver enzymes, renal function tests, and lactate. Further evaluation included a normal chest radiograph, normal transthoracic echocardiogram, negative sepsis evaluation, and an electroencephalogram, which was obtained as a routine evaluation for hypoxic ischemic encephalopathy status after the subject's code event. The electroencephalogram demonstrated diffuse slowing consistent with non- 


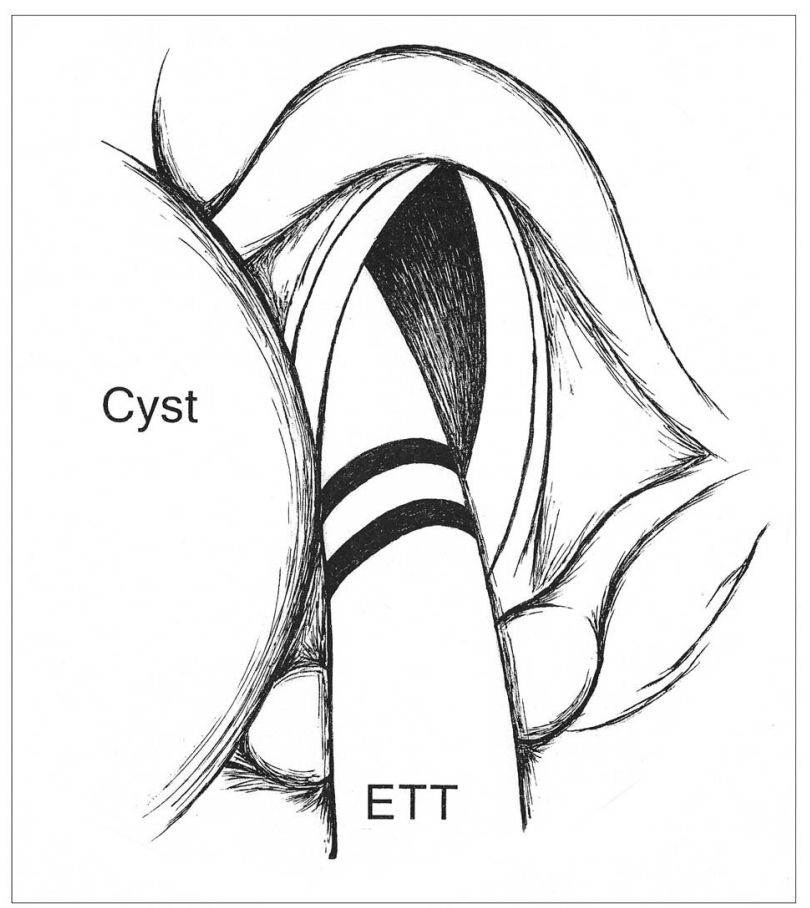

Fig. 1. Schematic of rigid bronchoscopy indicating anterolateral displacement of the airway and epiglottis to the right of the image by apparent tongue mass. A large tongue mass is shown at the left of the image. ETT = endotracheal tube.

specific encephalopathy, likely secondary to medication effect.

Throughout his pediatric ICU course, the subject required minimal ventilatory support and had no evidence of lung disease as the etiology for his respiratory failure. Because of concern for upper-airway obstruction, the subject was evaluated in the operating room. Rigid bronchoscopy suggested the presence of a large tongue mass that displaced the airway and epiglottis anterolaterally, but complete visualization and further characterization were not possible (Fig. 1). Flexible bronchoscopy revealed similar findings, and magnetic resonance imaging was then performed to better delineate the anatomic abnormality, presumed to be either a lingual thyroglossal duct cyst or lingual thyroid. Magnetic resonance imaging revealed a $1.0 \mathrm{~cm} \times 1.1 \mathrm{~cm} \times 1.2 \mathrm{~cm}$ non-enhancing mass at midline at the base of the tongue that displaced the endotracheal tube rightward (Fig. 2). Normally positioned thyroid tissue was noted, and the lesion was presumed to be a thyroglossal duct cyst.

The subject then underwent repeat direct laryngoscopy and marsupialization of the lesion, and pathology was consistent with a thyroglossal duct cyst. He was subsequently extubated to nasal CPAP and quickly weaned to room air. Two days after extubation, he was transferred to the general pediatrics ward for ongoing management and was

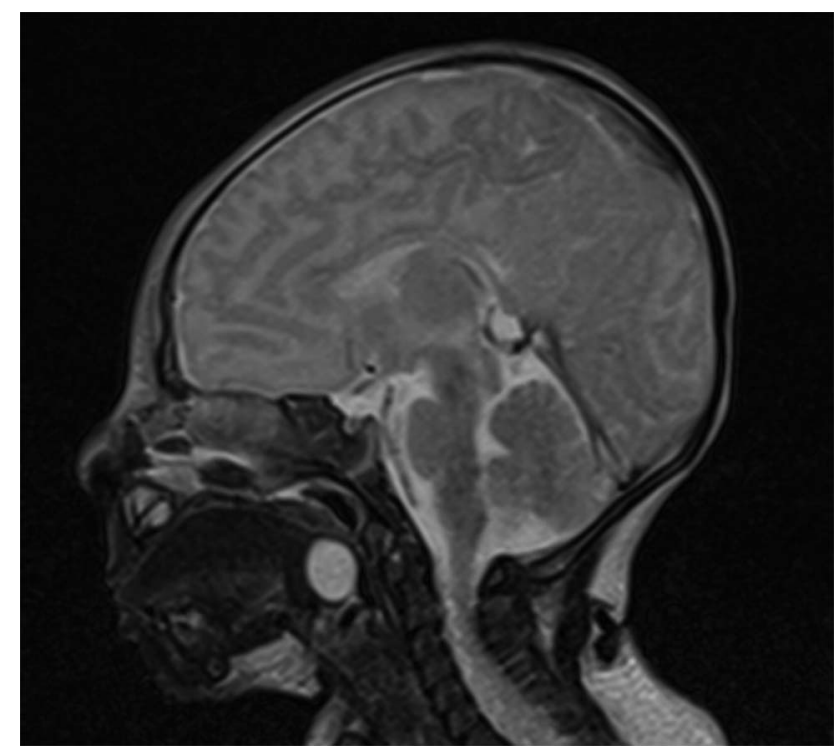

Fig. 2. Magnetic resonance imaging demonstrates a $1.0 \mathrm{~cm}$ $\times 1.1 \mathrm{~cm} \times 1.2 \mathrm{~cm}$ T2-weighted hyperintense, non-enhancing mass at midline at the base of the tongue.

Table 1. Potential Causes of Upper-Airway Obstruction by Typical Age

\begin{tabular}{ll}
\hline \hline \multicolumn{1}{c}{$\begin{array}{c}\text { Neonates and Infants } \\
(0-12 \text { months old })\end{array}$} & \multicolumn{1}{c}{$\begin{array}{c}\text { Toddlers and Preschoolers } \\
(1-5 \text { y old })\end{array}$} \\
\hline $\begin{array}{l}\text { Choanal atresia/stenosis } \\
\text { Laryngomalacia/tracheomalacia/ } \\
\text { stenosis }\end{array}$ & $\begin{array}{l}\text { Tonsillar and adenoid enlargement } \\
\text { Croup }\end{array}$ \\
$\begin{array}{l}\text { Vascular ring/sling } \\
\text { Airway masses (eg, vascular } \\
\text { malformations, papillomas, } \\
\text { cysts) }\end{array}$ & $\begin{array}{l}\text { Bacterial tracheitis } \\
\text { Retropharyngeal abscess }\end{array}$ \\
Tracheal/laryngeal webs & Foreign body \\
\hline
\end{tabular}

ultimately discharged home without need for respiratory support.

\section{Discussion}

This report describes an infant with acute respiratory failure secondary to upper-airway obstruction. Given the wide differential diagnosis for respiratory distress in neonates, upper-airway obstruction is often not the first consideration as a potential etiology beyond the immediate newborn period..$^{5,6}$ Infants with upper-airway obstruction most commonly present with stridor, and although the differential diagnosis of airway obstruction is broad, the most likely etiology for upper-airway obstruction in a previously health infant is laryngomalacia (Table 1). ${ }^{5}$

In this case, airway obstruction was secondary to a lingual thyroglossal duct cyst. This lesion is an uncommon 


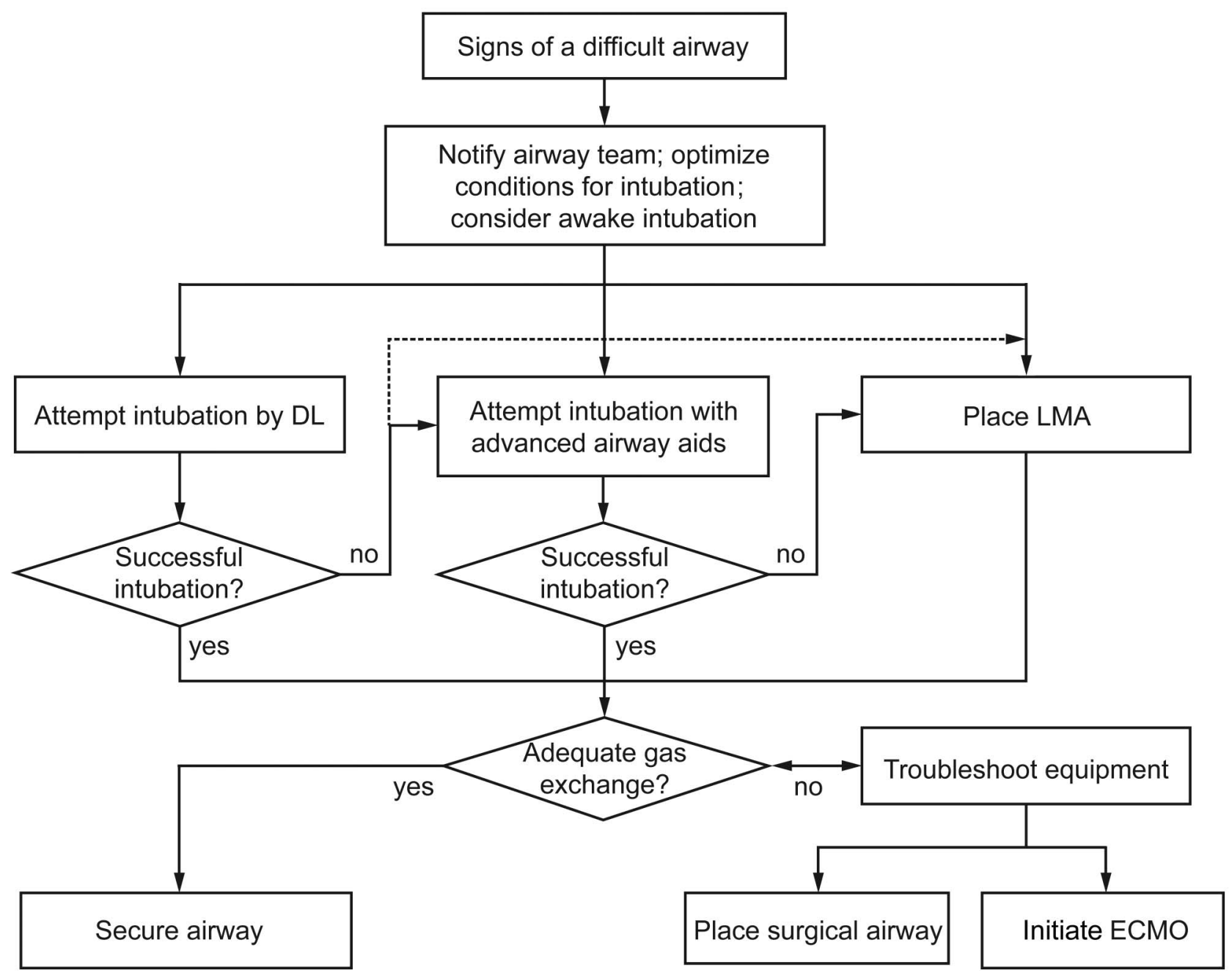

Fig. 3. Difficult-airway algorithm. See also the American Society of Anesthesiologists' difficult-airway algorithm. ${ }^{17}$ Optimal conditions include adequate positioning, availability of an oral airway and a variety of laryngoscope blades and endotracheal tub sizes, as well as the presence of an experienced provider. Advanced aids include fiberoptic bronchoscope or video laryngoscope. $\mathrm{DL}=$ direct laryngoscopy; $\mathrm{LMA}=$ laryngeal mask airway; ECMO = extracorporeal membrane oxygenation.

congenital anomaly, comprising only $0.6-3 \%$ of thyroglossal duct remnants, which occur in 700 of 10,000 births. $^{7}$ Lingual cystic remnants of the thyroglossal duct result from canalization of an epithelial remnant that connects the migrating thyroid gland to the foramen cecum of the tongue, leading to subsequent mucous production and resulting cyst formation. ${ }^{8}$ Although rare, these anomalies may cause fixed or dynamic upper-airway obstruction by a ball-valve mechanism between the cyst and the laryngeal inlet. ${ }^{9}$

Compared with other thyroglossal duct remnant diseases, which most commonly present as midline neck masses in the setting of superinfection, ${ }^{3}$ lingual cysts may preclude routine identification due to their more obscure location. In a series reported by Bai et al, ${ }^{10}$ only one of 9 cysts was identified by tongue spatula, with 8 of 9 cysts being identified by laryngoscopy. However, identification with a la- ryngoscope is not always possible. In addition, as in this case, preceding symptoms may be subtle and nonspecific, including dysphonia ${ }^{7}$ or mild feeding difficulties. ${ }^{11}$ If unidentified, the presence of a lingual thyroglossal duct cyst causing upper-airway obstruction may be associated with significant risk for mortality. ${ }^{12,13}$ Several case reports describe an infant death initially presumed to be due to sudden infant death syndrome but subsequently thought to be attributable to large lingual thyroglossal duct cysts. ${ }^{8,14,15}$ Thus, a high index of suspicion for this possible lesion is necessary in infants who present with signs and symptoms of upper-airway obstruction. ${ }^{16}$ If suspected, further workup should include evaluation by a pediatric otolaryngologist and cross-sectional imaging with either computed tomography or magnetic resonance imaging. ${ }^{3}$ Surgical intervention for a lingual thyroglossal duct cyst can be curative. However, prior to surgical intervention, one must confirm 


\section{Acute Upper-Airway Obstruction by a Lingual Thyroglossal Duct Cyst}

normal placement and functioning of thyroid tissue given the possibility of lingual thyroid presenting similarly on cross-sectional imaging. ${ }^{7}$

As indicated by this case, the etiology of upper-airway obstruction may be obscure in an infant presenting with acute respiratory compromise. Thus, recognition of the potential for a difficult airway and need for advanced airway management is central to preventing potential morbidity and mortality. The American Society of Anesthesiologists' "Practice Guidelines for Management of the Difficult Airway" suggest that although "there is insufficient published evidence to evaluate the effect of a bedside medical history or predicting the presence of a difficult airway ... there is suggestive evidence that some features of a patient's medical history ... may be related to the likelihood of encountering a difficult airway." 17 In addition to a suggestive history, ${ }^{4,11,12}$ features of the physical examination could also be a clue to the possibility of a difficult airway. ${ }^{17,18}$ The suggestive historical clues include difficulty with feeding, stridor, respiratory distress of acute-onset, positional change in work of breathing, and history of a difficult intubation. Physical examination features suggestive of a difficult airway include micrognathia, macroglossia, glossoptosis, short neck or limited range of motion, highly arched or narrowed palate, midface hypoplasia, and respiratory distress in the absence of adequate air entry. In the case of suggestive history or physical examination, practice guidelines suggest benefit from a preplanned strategy consisting of early notification of a specialized airway team, refraining from paralysis until capacity to control ventilation is certain, and available alternatives to endotracheal intubation with rigid laryngoscopy (Fig. 3). ${ }^{17,19}$

Existing alternatives to endotracheal intubation with rigid laryngoscopy include various tools for fiberoptic-guided intubation and intubation via video laryngoscopy. These options improve the view of the larynx and may therefore minimize the trauma of and risk for prolonged hypoventilation associated with repeated attempts at direct laryngoscopy. However, the use of these aids requires the adoption and maintenance of an additional skill set to manipulate the endotracheal tube through the vocal cords under indirect visualization. ${ }^{19}$ Furthermore, these tools are often not readily available, and additional delay of adequate gas exchange may be avoided by placement of a laryngeal mask airway. Laryngeal mask airways are more readily available, are easily placed, and may facilitate adequate gas exchange while awaiting specialist assistance for a more definitive airway in the setting of difficult intubation. In rare cases, such as in some airway lesions below the vocal cords, ${ }^{19}$ an appropriately positioned laryngeal mask airway is ineffective in restoring ventilation, and a surgical airway may be required. ${ }^{20}$ Most commonly, this surgical airway is placed by trained personnel via needle cricothy- roidotomy. ${ }^{21}$ Alternatively, extracorporeal membrane oxygenation may be needed as a bridge to definitive surgical intervention in neonates, infants, and children with significant upper-airway obstruction in whom an artificial airway cannot be established.22,23

This case demonstrates that awareness and planning are important for all patients with acute respiratory distress, given the potential risk for a difficult airway, even when there are no clear suggestive historical or physical examination features. Evidence suggests that the incidence of a difficult airway is $1-18 \%$ in adults ${ }^{24-26}$ and may be as high as $15 \%$ in neonatal and pediatric patients. ${ }^{27,28}$ Additionally, adult and pediatric studies have described significant morbidity and mortality associated with advanced airway management, with adverse events occurring in $14-47 \%$ of intubations. ${ }^{25,29,30}$ Although respiratory distress is a common presentation in neonates, ${ }^{6,31}$ practitioners should be vigilant in considering a broad differential diagnosis, including uncommon diagnoses such as upper-airway obstruction. In the event that advanced airway support is necessary, appropriate recognition of and preparation for a difficult intubation may prevent significant morbidity and mortality for patients with acute respiratory failure.

\section{Teaching Points}

- In the setting of a difficult airway, repeated attempts at intubation may lead to inability to ventilate. Early use of a laryngeal mask airway and/or more advanced visual aids (fiberoptic bronchoscopy, video laryngoscopy) may restore ventilation and be lifesaving.

- Lingual thyroglossal duct cysts are an uncommon cause of neonatal upper-respiratory obstruction and require a high index of suspicion for appropriate diagnosis. Upper-airway obstruction should be considered in the differential diagnosis of neonatal respiratory distress.

\section{REFERENCES}

1. Jardine D, Bhutta OJ, Inglis A. Specific diseases of the respiratory system: upper airway. In: Fuhrman BP, Zimmerman JJ, editors. Pediatric Critical Care, 4th edition. Philadelphia: Elsevier; 2011:561574.

2. Young KD, Seidel JS. Pediatric cardiopulmonary resuscitation: a collective review. Ann Emerg Med 1999;33(2):195-205.

3. Laya BF, Lee EY. Congenital causes of upper airway obstruction in pediatric patients: updated imaging techniques and review of imaging findings. Semin Roentgenol 2012;47(2):147-158.

4. Sasidaran K, Bansal A, Singhi S. Acute upper airway obstruction. Indian J Pediatr 2011;78(10):1256-1261.

5. Kier C, Balluz R, Modi V, Chandran L. Visual diagnosis: respiratory distress: a great masquerader. Pediatr Rev 2011;32(10):e95-e101.

6. Warren JB, Anderson JM. Newborn respiratory disorders. Pediatr Rev 2010;31(12):487-495.

7. Sameer KS, Mohanty S, Correa MM, Das K. Lingual thyroglossal duct cysts-a review. Int J Pediatr Otorhinolaryngol 2012;76(2):165168. 


\section{Acute Upper-Airway Obstruction by a Lingual Thyroglossal Duct Cyst}

8. Byard RW, Bourne AJ, Silver MM. The association of lingual thyroglossal duct remnants with sudden death in infancy. Int J Pediatr Otorhinolaryngol 1990;20(2):107-112.

9. Weldon BC, Krafcik JM. Breath-holding-like spells in an infant: an unusual presentation of lingual thyroglossal duct cyst. J Pediatr Surg 2000;35(9):1381-1384.

10. Bai W, Ji W, Wang L, Song Y. Diagnosis and treatment of lingual thyroglossal duct cyst in newborns. Pediatr Int 2009;51(4):552-554.

11. Miller CK, Willging, JP. The implications of upper-airway obstruction on successful infant feeding. Semin Speech Lang 2007;28(3): 190-203.

12. Eom M, Kim YS. Asphyxiating death due to basal lingual cyst (thyroglossal duct cyst) in two-month-old infant is potentially aggravated after central catheterization with forced positional changes. Am J Forensic Med Pathol 2008;29(3):251-254.

13. Sauvageau A, Belley-Côté ÉP, Racette S. Fatal asphyxia by a thyroglossal duct cyst in an adult. J Clin Forensic Med 2006;13(6-8): 349-352.

14. Kanawaku Y, Funayama M, Sakai J, Nata M, Kanetake J. Sudden infant death: lingual thyroglossal duct cyst versus environmental factors. Forensic Sci Int 2006;156(2-3):158-160.

15. Hanzlick RL. Lingual thyroglossal duct cyst causing death in a fourweek-old infant. J Forensic Sci 1984;29(1):345-348.

16. Paez P, Warren WS, Srouji MN. Stridor as the presenting symptom of lingual thyroglossal duct cyst in an infant. Clin Pediatr 1974; 13(12):1077-1078.

17. American Society of Anesthesiologists Task Force on Management of the Difficult Airway. Practice guidelines for management of the difficult airway: an updated report by the American Society of Anesthesiologists Task Force on Management of the Difficult Airway. Anesthesiology 2003;98(5):1269-1277.

18. Infosino A. Pediatric upper airway and congenital anomalies. Anesthesiol Clin North America 2002;20(4):747-766.

19. Sims C, von Ungern-Sternberg BS. The normal and the challenging pediatric airway. Paediatr Anaesth 2012;22(6):521-526.

20. Heard AM, Green RJ, Eakins P. The formulation and introduction of a 'can't intubate, can't ventilate' algorithm into clinical practice. Anaesthesia 2009;64(6):601-608.
21. Coté CJ, Hartnick CJ. Pediatric transtracheal and cricothyrotomy airway devices for emergency use: which are appropriate for infants and children? Paediatr Anaesth 2009;19(Suppl 1):66-76.

22. Goldman AP, Macrae DJ, Tasker RC, Edberg KE, Mellgren G, Herberhold $\mathrm{C}$, et al. Extracorporeal membrane oxygenation as a bridge to definitive tracheal surgery in children. J Pediatr 1996; 128(3):386-388.

23. Huang SC, Wu ET, Chi NH, Chiu SN, Huang PM, Chen YS, et al. Perioperative extracorporeal membrane oxygenation support for critical pediatric airway surgery. Eur J Pediatr 2007;166(11):1129-1133.

24. Ovassapian A, Glassenberg R, Randel GI, Klock A, Mesnick PS, Klafta JM. The unexpected difficult airway and lingual tonsil hyperplasia: a case series and a review of the literature. Anesthesiology 2002;97(1):124-132

25. Egan TD, Wong KC. Predicting difficult laryngoscopy for tracheal intubation: an approach to airway assessment. Ma Zui Xue Za Zhi 1993;31(3):165-178.

26. Deller A. [Incidence and predictability of difficult intubation]. Anasthesiol Intensivmed Notfallmed Schmerzther 1995;30(3):169-171. Article in German.

27. Nishisaki A, Ferry S, Colborn S, DeFalco C, Dominguez T, Brown CA 3rd, et al. Characterization of tracheal intubation process of care and safety outcomes in a tertiary pediatric intensive care unit. Pediatr Crit Care Med 2012;13(1):e5-e10.

28. Blanco G, Melman E, Cuairan V, Moyao D, Ortiz-Monasterio F. Fibreoptic nasal intubation in children with anticipated and unanticipated difficult intubation. Paediatr Anaesth 2001;11(1):49-53.

29. Cook TM, Woodall N, Harper J, Benger J. Major complications of airway management in the UK: results of the Fourth National Audit Project of the Royal College of Anaesthetists and the Difficult Airway Society. Part 2: intensive care and emergency departments. Br J Anaesth 2011;106(5):632-642.

30. Gausche M, Lewis RJ, Stratton SJ, Haynes BE, Gunter CS, Goodrich SM, et al. Effect of out-of-hospital pediatric endotracheal intubation on survival and neurological outcome: a controlled clinical trial JAMA 2000;283(6):783-790.

31. Nitu ME, Eigen H. Respiratory failure. Pediatr Rev 2009;30(12): 470-477. 